\title{
Avaliação dos parâmetros microbiológicos e físico-químicos de poços individuais no município de Barcarena/PA
}

Águas subterrâneas podem ser atingidas de diversas formas pela ação antrópica, impactando diretamente em sua qualidade e composição, podendo trazer efeitos deletérios a população abastecida por estes poços. O Município de Barcarena pertence à Mesorregião Metropolitana de Belém teve seu crescimento econômico baseado na implantação de grandes projetos industriais. No entanto, apesar deste crescimento, o município possui falta de infraestrutura, adensamento populacional, e uso e ocupação do solo inadequada com degradação de seus recursos hídricos. Para avaliar o impacto destas atividades, este trabalho teve como objetivo determinar a qualidade da água proveniente de poços individuais consumida pelas famílias residentes na região próxima à área industrial de Barcarena-PA de acordo com os parâmetros físico-químicos e microbiológicos e as condiç̃̃es de potabilidade previstas no Anexo XX da Portaria de Consolidação no 5 de 28/09/2017 do Ministério da Saúde. O estudo revelou que em um número amostral de 50 poços, $100 \%$ das amostras não atendiam as condições de potabilidade previstas na legislação acima citada, sendo que para os parâmetros microbiológicos, foi detectada a presença de Coliformes totais em $84 \%$ das amostras e $54 \%$ apresentaram potabilidade previstas na legislação acima citada, sendo que para os parâmetros microbiológicos, foi detectada a presença de Coliformes totais em $84 \%$ das amostras e $54 \%$ apresentaram do $\mathrm{pH}$, que alcançou $90 \%$, seguida do parâmetro de cor aparente que representou em $42 \%$ das reprovações. Considerando-se ainda a contaminação dos poços por E. coli foi verificado que poços com maior $\mathrm{pH}$ tem mais chances de serem contaminados por E. coli. Portanto, é possível apontar a fragilidade do recurso hídrico, cuja qualidade da água pode estar estreitamente associada à profundidade do poço para captação da água, vulnerabilidade ambiental local, infiltração e lixiviação ocorridas nesta região.

Palavras-chave: Águas subterrâneas; Qualidade da água; Potabilidade.

\section{Evaluation of microbiological and physical-chemical parameters of individual wells in the city of Barcarena/PA}

Groundwater can be reached in different ways by anthropic action, directly influencing its quality and composition, and can bring harmful effects to the population supplied by these wells. The city of Barcarena belongs to the Metropolitan Mesoregion of Belém had its economic growth based on the implementation of large industrial projects. However, despite this growth, the city has a lack of infrastructure, population density, and inadequate land use and occupation with degradation of its water resources. To assess the impact of these activities, this work aimed to determine the quality of water from individual wells consumed by families living in the region close to the industrial area of Barcarena-PA according to the physical-chemical and microbiological parameters and the drinking conditions provided for in Annex XX of Consolidation Ordinance No. 5 of 09/28/2017 of the Ministry of Health. The study revealed that in a sample number of 50 wells, $100 \%$ of the samples did not meet the drinking conditions provided for in the aforementioned legislation, being that for microbiological parameters, the presence of total coliforms was detected in $84 \%$ of the samples and $54 \%$ showed contamination by Escherichia coli in the analyzed wells. When evaluating the outcome of the analysis of the physicalchemical parameters, the highest percentage of non-compliance was due to the $\mathrm{pH}$, which reached $90 \%$, followed by the apparent color parameter that represented $42 \%$ of failures. Considering also the contamination of the wells by E. coli, it was found that wells with a higher $\mathrm{pH}$ are more likely to be contaminated by E. coli. Therefore, it is possible to point out the fragility of the water resource, whose water quality can be closely associated with the depth of the well to collect water, local environmental vulnerability, infiltration and leaching that occurred in this region.

Keywords: Groundwater; Water quality; Potability.

Topic: Uso de Recursos Naturais

Reviewed anonymously in the process of blind peer.
Received: 03/02/2021

Approved: $26 / 02 / 2021$
Danielle Nazaré Salgado Mamede Pantoja (iD Universidade do Estado do Pará, Brasil http://lattes.cnpq.br/2293923003896598 http://orcid.org/0000-0001-9795-2726 danielle.salgado@hotmail.com

Hebe Morganne Campos Ribeiro (D) Universidade do Estado do Pará, Brasil http://lattes.cnpq.br/2399134205919272 http://orcid.org/0000-0001-7154-9947 hebemcr@gmail.com

Rosane do Socorro Pompeu de Loiola Universidade do Estado do Pará, Brasil http://lattes.cnpq.br/8444597777693178 http://orcid.org/0000-0002-5545-8188 rosaneloiola@gmail.com

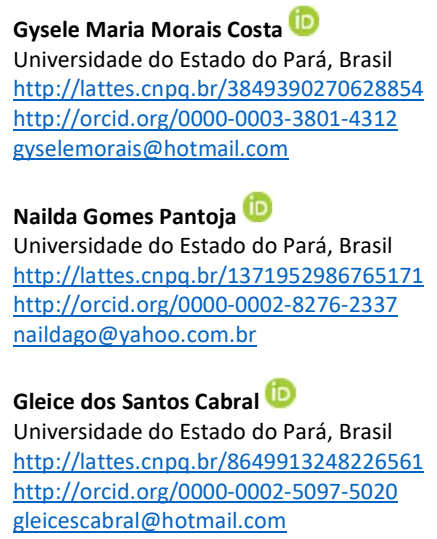

Layse Gomes Furtado (it

Universidade do Estado do Pará, Brasil http://lattes.cnpq.br/0901784538651766 http://orcid.org/0000-0002-2442-0945 layse.furtadog@gmail.com

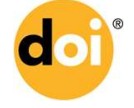

DOI: 10.6008/CBPC2179-6858.2021.002.0048
Referencing this:

PANTOJA, D. N. S. M.; RIBEIRO, H. M. C.; LOIOLA, R. S. P.; COSTA, G. M. M.; PANTOJA, N. G.; CABRAL, G. S.; FURTADO, L. G.. Avaliação dos parâmetros microbiológicos e físico-químicos de poços individuais no município de Barcarena/PA. Revista Ibero Americana de Ciências Ambientais, v.12, n.2, p.557-566, 2021. DOI: http://doi.org/10.6008/CBPC2179-6858.2021.002.0048 


\section{INTRODUÇÃO}

A poluição das águas é, principalmente, fruto da ação antrópica e os poluentes atingem águas superficiais e subterrâneas de diversas formas (SATTERTHWAITE et al., 2010). Entre os sítios de contaminação ambiental, as fontes de água se tornaram um dos graves problemas na região amazônica, devido à poluição desregulada e o descarte antropogênico, merecendo estudos mais detalhados, considerando que as mudanças na composição da água podem ter efeitos deletérios aos organismos que habitam estas áreas e para a saúde humana (OHE et al., 2004; OLIVERO-VERBEL et al., 2016).

No que concerne aos resíduos despejados pela indústria e atividade mineradora, não somente o volume, mas principalmente sua composição química, tem um papel importante em termos do risco ocasionado ao ambiente (SMAKA-KINCL et al., 1996). Neste contexto, a mineração no Estado Pará, particularmente no município de Barcarena, se destaca como o principal fator de impacto ambiental causado pelo beneficiamento dos minérios, que geram rejeitos em grandes toneladas e de difícil decomposição.

O município de Barcarena, que pertencente à Mesorregião Metropolitana de Belém e a Microrregião de Belém, teve seu crescimento econômico a partir de grandes projetos na década de 80, que proporcionou a instalação do complexo industrial - portuário de beneficiamento de bauxita e caulim (SILVA et al., 2019). No entanto, apesar do crescimento, o município pouco apresentou o desenvolvimento econômico, refletindo na falta de infraestrutura, adensamento populacional, no uso e ocupação do solo inadequado e na degradação dos recursos hídricos (ALVES et al., 2015). Como resultado, a atividade de mineração neste município tem causado frequentemente impactos ambientais, os quais são relatados pela população e autoridades locais (SILVA et al., 2018).

Diante desse cenário, ressaltam-se recorrentes danos ao meio ambiente, como os casos de poluição dos principais rios e igarapés da região, essenciais para a vida das comunidades tradicionais. Estes são usados atualmente como meros depositários dos dejetos produzidos pelas atividades industriais em seu leito gerando envenenamento e poluição (FERREIRA, 2015).

Associado à baixa qualidade das águas superficiais, outro recurso que também vem sofrendo degradação são os de águas subterrâneas, tornando-se cada vez mais reduzida a quantidade de mananciais de água em condições de vazão e qualidade compatíveis com o abastecimento da população (OMS, 2011). Diversas avaliações dos impactos da urbanização sobre os mananciais subterrâneos têm sido realizadas, como os potenciais impactos de fossas sépticas sobre a qualidade das águas subterrâneas em diversos aquíferos e ainda estudos sobre impactos da urbanização na qualidade da água subterrânea (KATZ et al., 2011; HAQUE et al., 2013).

A água é utilizada para vários fins no ciclo da vida humana e não humana. Ela é essencial na agricultura, indústria, mineração, serviços, mas fundamentalmente é imprescindível no consumo direto. Os primeiros registros do aproveitamento da água subterrânea são incertos, datando aproximadamente de 2000 a.C., em estruturas de poços e túneis (SALIH, 2006). Na Amazônia, nas proximidades dos grandes rios, onde se situam as cidades ribeirinhas, a solução mais utilizada é a construção de poços com seç̧ões pré- 
fabricadas, que evitam o desmoronamento de sua parede, denominada de poços do tipo Amazonas (DACACH, 1975). Porém está água para ser consumida precisa estar sob qualidade que não traga riscos para a saúde, condição conhecida como água potável (MAIA, 2017). A água potável pode ser definida como água para consumo humano cujos parâmetros físicos, químicos e microbiológicos atendam ao padrão de potabilidade e não ofereça riscos à saúde (BRASIL, 2017).

Um dos maiores problemas de saúde no mundo, encontrados principalmente em países em desenvolvimento, são as doenças transmitidas pela água. Estas se encontram contaminadas por vários tipos de microrganismos saprófitas, cujo habitat natural pode ser o solo, a água ou o ar e por microrganismos patogénicos em resultado de contaminação com esgotos domésticos contendo matérias fecais (LUCAS et al., 2011). A implantação de sistemas públicos de água tratada e de esgotos reduz drasticamente os casos de doenças infeciosas. Contudo, as águas provenientes da bica, fontes, poços, incluindo os artesianos, são responsáveis por surtos notificados veiculados pela água (CABRAL, 2010).

E assim, considerando que a população deste município em sua grande maioria encontra-se abastecida por águas de poços provenientes de soluções individuais, este trabalho teve como objetivo avaliar a qualidade destes poços cuja água é consumida pelas famílias residentes na região próxima à área industrial de Barcarena-PA de acordo com os parâmetros físico-químicos e microbiológicos.

\section{MATERIAIS E MÉTODOS}

A área monitorada foi o município de Barcarena situado no Estado do Pará, pertencente a mesorregião metropolitana de Belém, que se localiza a 01930'21" de latitude sul e 48ㅇㄱ'33' de longitude oeste. Foram analisadas 50 amostras de água coletadas em poços de solução alternativa individual no ano de 2018, cujos resultados encontram-se disponíveis na base de dados do Laboratório Central do Estado do Pará. A área de estudo envolveu as comunidades localizadas no polo industrial deste município nos bairros de Vila Itupanema, Jardim Cabano e Laranjal, apresentada na figura 1.

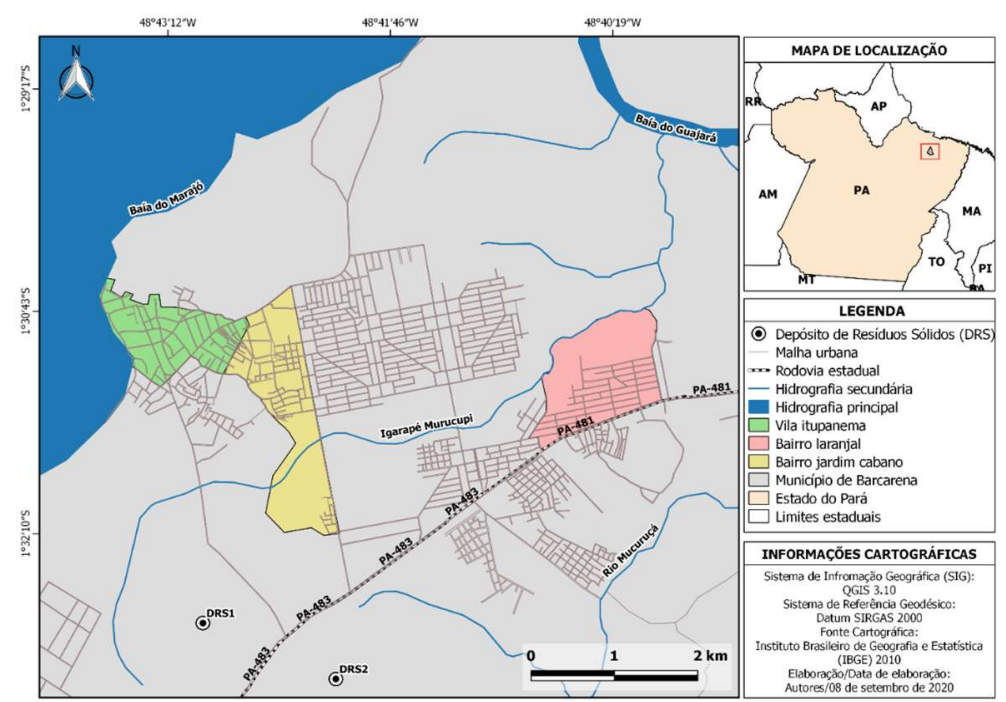

Figura 1: Bairros da área de coleta de amostras no município de Barcarena/PA.

Os parâmetros físico-químicos e microbiológicos foram avaliados como critérios de potabilidade da 
água de acordo com o anexo XX da Portaria ${ }^{\circ} 5$ de 28 de setembro de 2017 do Ministério da Saúde (BRASIL, 2017). A coleta seguiu o padrão descrito no Guia Nacional de Coleta e Preservação de Amostras da CETESB (2011), sendo que o volume de amostra de água dos poços foi coletado diretamente usando frascos estéreis em amostra única. Um saco de 100 mililitros foi usado para acondicionar as amostras para a avaliação microbiológica e um saco com capacidade de 532 mililitros foi usado para acondicionar as amostras referente a cada ponto de coleta para a realização dos parâmetros de dureza, $\mathrm{pH}$, turbidez, cor aparente da agua, sólidos totais dissolvidos, teor de cloreto, teor de amônia, teor de nitrato, teor de nitrito, teor de sulfato e ferro. Estes sacos coletores foram transportados sob refrigeração em caixa térmica contendo gelo reciclado até sua chegada ao laboratório.

Para determinação de coliformes totais e E. coli aplicou-se o método de substrato cromogênico enzimático, usando o reagente Collilert da IDEXX Laboratories, Inc., de acordo com as recomendações do fabricante. A identificação da presença de E. coli foi feita usando luz ultravioleta e seguiram as recomendações descritas no Standard Methods for Examination of Water and Wastewater (APHA, 2017).

Para determinação de parâmetros físico-químicos, o parâmetro de $\mathrm{pH}$ foi mensurado pelo método da potenciometria usando um medidor de $\mathrm{pH}$ de bancada digital com compensação manual de temperatura da marca Analion modelo PM608. A determinação dos sólidos totais dissolvido foi realizada pelo método da condutivimetria usando o medidor de condutividade elétrica Orion Star da Thermo Scientific Orion série A212 com faixa de resolução 1 a 200 ppt. A turbidez das amostras de água foi aferida pelo método nefelométrico usando o turbidímetro digital da Hach modelo 2100AN. A determinação dos teores de nitrato, nitrito e sulfato foi realizada por reação colorimétrica e com leituras da intensidade de cor realizada no espectrofotômetro da HACH DR 3900. O teor de cloreto foi verificado pelo método titulação usando como indicador o cromato de potássio a $5 \%$ e como solução titulante o nitrato de prata a 0,014N. O teor de amônia foi determinado através do reagente de Nessler e o produto da reação foi verificado no espectrofotômetro HACH DR 3900, equipamento também utilizado para determinação da cor aparente por espectometria. A dureza foi determinada por titulação com EDTA e para determinação do ferro foi utilizada espectrometria de emissão ótica com plasma indutivamente acoplado e seguiram as recomendações descritas no Standard Methods for Examination of Water and Wastewater (APHA, 2017).

Os dados foram submetidos às análises de testes não paramétricos como, a estatísticas descritivas, de correlação de Pearson e do teste-T de Student envolvendo os dados dos parâmetros físico-químicos e microbiológicos. O software utilizado foi o Bioestat 5.0 de Ayres et al. (2007) e a significância estatística aceita foi ao nível de $5 \%$.

\section{RESULTADOS}

A avaliação da qualidade da água de poços utilizados como fonte alternativa individual para o consumo humano na área industrial do município de Barcarena-PA revelou que em um número amostral de 50 poços, $100 \%$ das amostras não atendiam as condições de potabilidade previstas na Portaria de Consolidação no 5 de 28/09/2017 do Ministério da Saúde. 
Considerando os parâmetros microbiológicos, foi detectada a presença de Coliformes totais em $84 \%$ (42/50) das amostras dos poços e em 54\% (27/50) das amostras apresentaram contaminação por Escherichia coli, conforme apresentada na figura 2. A legislação vigente determina que não seja tolerável a presença deste último micro-organismo devido ao risco de adoecimento pela população tornando-a, assim, imprópria para consumo humano.

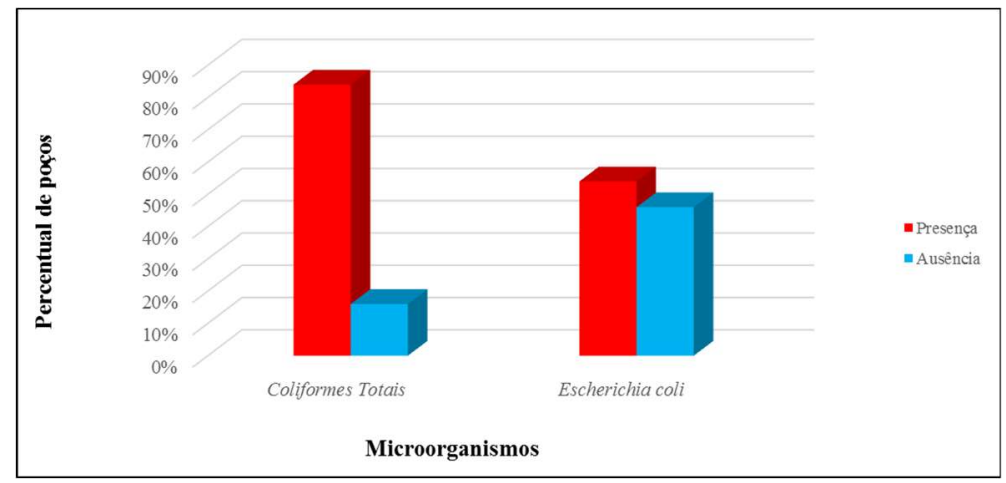

Figura 2: Frequência de microrganismos detectados em amostras de água coletadas de solução alternativa individual (poços) no distrito industrial do município de Barcarena-PA em 2018.

Para as médias dos valores dos parâmetros físico-químicos, foram observados valores máximos acima do permitido pela legislação brasileira, em relação aos parâmetros teor de amônia, cor aparente, ferro dissolvido, nitrato e turbidez. O coeficiente de variação ficou entre $12,50 \%$ a 212,96\% relativo ao $\mathrm{pH}$ e ao ferro dissolvido, respectivamente, conforme apresentado na tabela 1. Estas variações foram responsáveis pela maioria das condições impróprias da água desses poços para o consumo humano, especialmente o pH da água que esteve abaixo da faixa indicada entre 6,0 e 9,5 para água potável.

Tabela 1: Avaliação descritiva dos parâmetros físico-químicos detectados em amostras de água coletadas de solução alternativa individual (poços) no distrito industrial do município de Barcarena-PA em 2018.

\begin{tabular}{|c|c|c|c|c|c|c|c|}
\hline Parâmetro & VMP & $\mathbf{N}$ & MIN & MAX & MEDIA & DP & CV (\%) \\
\hline Amônia & $1,5 \mathrm{mg} / \mathrm{L}$ & 50.0 & 0.01 & 3.80 & 0.45 & 0.77 & $171.77 \%$ \\
\hline Cloreto & $250.0 \mathrm{mg} / \mathrm{L}$ & 50.0 & 5.00 & 56.00 & 24.24 & 11.13 & $45.91 \%$ \\
\hline Cor Aparente & $15 \mathrm{uH}$ & 50.0 & 0.00 & 259.00 & 23.50 & 44.48 & $189.27 \%$ \\
\hline Dureza & $500 \mathrm{mg} / \mathrm{L}$ & 50.0 & 10.00 & 80.20 & 40.57 & 17.14 & $42.24 \%$ \\
\hline Ferro Dissolvido & $0.3 \mathrm{mg} / \mathrm{L}$ & 50.0 & 0.00 & 1.38 & 0.09 & 0.20 & $212.96 \%$ \\
\hline Nitrato & $10.0 \mathrm{mg} / \mathrm{L}$ & 50.0 & 0.00 & 12.40 & 3.91 & 2.51 & $64.22 \%$ \\
\hline Nitrito & $1.0 \mathrm{mg} / \mathrm{L}$ & 50.0 & 0.00 & 0.03 & 0.01 & 0.01 & $52.44 \%$ \\
\hline $\mathrm{pH}$ & 6.0 a 9.5 & 50.0 & 4.04 & 6.62 & 4.90 & 0.61 & $12.50 \%$ \\
\hline SDT & $1000 \mathrm{mg} / \mathrm{L}$ & 50.0 & 7.64 & 183.20 & 56.41 & 40.44 & $71.69 \%$ \\
\hline Sulfato total & $250.0 \mathrm{mg} / \mathrm{L}$ & 50.0 & 0.00 & 45.00 & 4.30 & 7.35 & $170.91 \%$ \\
\hline Turbidez & $5.0 \mathrm{uT}$ & 50.0 & 0.32 & 46.30 & 3.54 & 6.57 & $185.24 \%$ \\
\hline
\end{tabular}

Na avaliação das análises dos parâmetros físico-químicos das águas consumidas dos poços, de forma individual, o maior percentual de insatisfatoriedade foi em decorrência do pH, que alcançou 90\% (45/50) das amostras de água, cuja medição demonstrou valores abaixo da faixa recomendado. O segundo parâmetro que resultou em análises insatisfatórias foi a cor aparente que representou 42\% (21/50) das reprovações, para nitrato $14 \%$ (7/50), teor de amônia 12\% (6/50) e turbidez com 8\% (4/50) dos casos de reprovações e por último o teor de ferro dissolvido que esteve acima do limite permitido de $0,3 \mathrm{mg} / \mathrm{L}$ em $2 \%$ (1/50) dos poços analisados, apresentado na figura 3. 


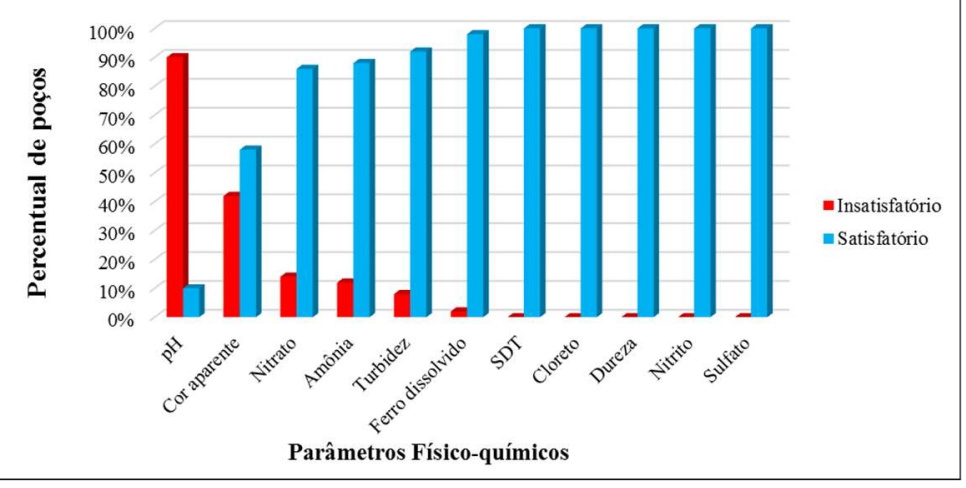

Figura 3: Desfecho das análises físico-químicas realizadas em amostras de água coletadas de solução alternativa individual (poços) no distrito industrial do município de Barcarena-PA em 2018.

Para efeito de compreensão das interações que podem ocorrer no ambiente, uma matriz de correlação entre todos os parâmetros físico-químicos e microbiológicos foi construída, segundo a tabela 2 . Assim, foram verificadas 18 correlações significativas e positivas entre alguns parâmetros, com correlação positiva mais acentuada entre cor aparente e turbidez e ainda cor aparente e nitrito.

Tabela 2: Correlação entre valores dos parâmetros físico-químicos e microbiológico detectados em amostras de água coletadas de solução alternativa individual (poços) no distrito industrial do município de Barcarena-PA em 2018.

\begin{tabular}{|c|c|c|c|c|c|}
\hline Parâmetro & Versus & Parâmetro & Coeficiente de correlação $r$ & Teste -t & p-valor \\
\hline Amônia & $\mathrm{x}$ & Cloreto & 0.4710 & 3.6988 & 0.0005 \\
\hline Amônia & $x$ & Sulfato & 0.4280 & 3.2806 & 0.0019 \\
\hline Amônia & $x$ & $\mathrm{pH}$ & 0.3509 & 2.5962 & 0.0124 \\
\hline Amônia & $x$ & SDT & 0.5229 & 4.2500 & $<0.0001$ \\
\hline Cor aparente & $x$ & Nitrato & 0.3495 & 2.5843 & 0.0128 \\
\hline Cor aparente & $\mathbf{x}$ & Nitrito & 0.6135 & 5.3828 & $<0.0001$ \\
\hline Cor aparente & $\mathbf{x}$ & Turbidez & 0.9036 & 14.6119 & $<0.0001$ \\
\hline Cor aparente & $x$ & E. coli & 0.2894 & 2.0945 & 0.0414 \\
\hline Cloreto & $x$ & Dureza & 0.3903 & 2.9371 & 0.0050 \\
\hline Cloreto & $x$ & Sulfato & 0.4768 & 3.7576 & 0.0005 \\
\hline Cloreto & $x$ & SDT & 0.5560 & 4.6344 & $<0.0001$ \\
\hline Nitrato & $x$ & Nitrito & 0.5157 & 4.1699 & 0.0001 \\
\hline Nitrito & $x$ & Turbidez & 0.5561 & 4.6351 & $<0.0001$ \\
\hline Nitrito & $x$ & Ferro & 0.2889 & 2.0909 & 0.0418 \\
\hline Sulfato & $x$ & $\mathrm{pH}$ & 0.3831 & 2.8731 & 0.0060 \\
\hline Sulfato & $x$ & SDT & 0.5156 & 4.1687 & 0.0001 \\
\hline $\mathrm{pH}$ & $x$ & E. coli & 0.2811 & 2.0297 & 0.0479 \\
\hline C. totais & $x$ & E. coli & 0.4729 & 3.7181 & 0.0005 \\
\hline
\end{tabular}

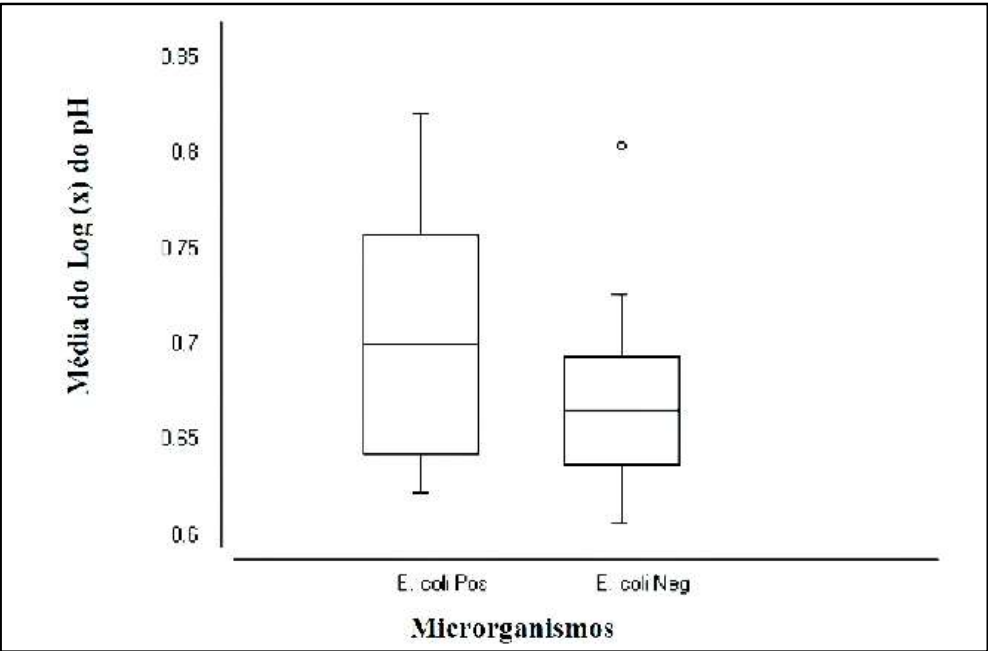

Figura 4: Comparação do nível do $\mathrm{pH}$ da água de poços com e sem a E. coli provenientes do Distrito industrial do município de Barcarena-PA em 2018. 
Analisando-se a contaminação dos poços por E. coli foi verificado se o pH da água podia favorecer ou não a presença desta bactéria no meio. A comparação entre o nível do $\mathrm{pH}$ da água de poços com e sem a $E$. coli, visto no boxplot apresentado na figura 4, demonstrou diferenças estatisticamente significativas pelo Teste-t $(\mathrm{t}=2,0209 ; p$-valor $=0,0479)$, evidenciando que poços com maior $\mathrm{pH}$ tem mais chances de serem contaminados por E. coli.

\section{DISCUSSÃO}

Neste estudo, a avaliação da qualidade da água de poços utilizados como fonte de abastecimento individual revelou que $100 \%$ deles estavam em condição imprópria para o consumo humano, considerando os parâmetros estabelecidos na Portaria de Consolidação no 5 de 28/09/2017 do Ministério da Saúde. A totalidade de amostras insatisfatórias encontrada pode ser igualmente demonstrada por estudos, como o realizado por Medeiros et al. (2016), em comunidades cuja a poluição da água está associada a locais com atividade industrial.

Em uma pesquisa realizada em uma importante província abastecida por águas subterrâneas no sul da Índia, onde houve uma explosão demográfica e um intenso crescimento das atividades agrícolas e industriais, observaram-se alterações nos padrões da qualidade da água para o consumo humano, onde foi evidenciado um aumento na concentração de ácidos fracos, bem como um aumento permanente da dureza da água, alterações na adsorção de sódio, carbonato de cálcio residual e na permeabilidade, evidenciando que em $56 \%$ das amostras coletadas na região com atividade industrial foram consideradas inadequadas para consumo humano (VASANTHAVIGAR et al., 2012).

No que concerne aos parâmetros microbiológicos, os resultados encontrados na pesquisa, se encontram em acordo com estudo realizado no Paquistão, onde a maioria das pessoas sem acesso à água potável, obtendo assim água a partir da fonte de água subterrânea, apresentou um maior número de casos de doentes, estabelecendo assim uma relação entre a qualidade da água bacteriológica e indicadores socioeconômicos com maior número de casos de gastroenterite na área de estudo (SHAHID et al., 2014).

De acordo com estudos realizados por Singh et al. (2015) na Índia, o crescimento da urbanização desordenada, assim como o desenvolvimento de pequenas e grandes industrias contribuem para a poluição das águas subterrâneas, um processo que pode explicar os dados observados nesta pesquisa. Medeiros et al. (2016), que avaliou duas comunidades da cidade de Barcarena, uma próxima ao polo industrial e outra mais fora de sua influência aponta maior poluição da água subterrânea entorno da Vila do Conde, local onde há maior atividade industrial e de grandes conglomerados urbanos. Ainda, para avaliar o efeito de fontes antropogênicas, um estudo conduzido por Oufline et al. (2012) no Marrocos que avaliou o impacto de três fontes de poluição (atividades de chorume, de águas residuais e de mineração), cujos resultados permitiram identificar que as águas subterrâneas e superficiais possuíam alterações em suas propriedades relacionadas às atividades anteriormente citadas.

Para os parâmetros físico-químicos pôde-se observar valores de pH baixos, que os quais refletem característica ácida, típico das aquíferas barreiras predominantes nesta região, e/ou ainda ao fato de que 
próximo a estas localidades há atividades recorrentes da mineração com potencial significativo para acidificar a água (OLIVEIRA FILHO et al., 2018).

A correlação evidenciada entre cor e turbidez pode ser explicada pelo fato de que ambas evidenciam partículas pequenas (coloides) em suspensão de origem orgânica destacando a presença de microorganismos patogênicos e ainda de origem inorgânica como areia e argila (SCALIZE et al., 2014), ressalta-se que neste estudo, $84 \%$ das amostras tinham pelo menos bactérias do grupo Coliformes totais. Foi ainda detectada uma correlação entre cor aparente e nitrito, devido ao nitrito está ligado à poluição antrópica, provavelmente através do despejo de esgotos em áreas com ocupação desregulada, como a ocorrida nas comunidades estudadas, ocasionando assim a mudança da cor aparente da água, tornando os compostos coloidais orgânicos mais evidentes, uma vez que os esgotos domésticos são uma das principais fontes de poluição química antrópica dos recursos hídricos nas áreas urbanas (BAIRD et al., 2011).

O nitrito, quando presente na água de consumo humano, pode ocasionar a metemoglobinemia independente da faixa etária do consumidor. A literatura referente aos estudos sobre a avaliação de compostos de nitrogênio em águas de poços no Brasil ainda é muito insipiente e poucos dados são divulgados em estudos epidemiológicos com respeito à metemoglobinemia, bem como, a ocorrência do desenvolvimento de alguns tipos de câncer devido à ingestão de teores elevados de nitrito (MEDEIROS et al., 2016).

A demonstração da relação estatisticamente significante entre valores de pH e presença do microorganismo E. coli está de acordo com Soares et al. (1999) que afirmam que o pH ótimo de crescimento para maioria das bactérias está em torno de 6,5 a 7,5. Sendo assim, valores de pH na faixa considerada ácida conferem uma maior proteção para água de poços de soluções alternativas individuais. Além disso, Silva et al. (2003), sugerem que poços com maiores profundidades, acima de $10 \mathrm{~m}$, apresentam pH mais baixos, e poços com pH mais alto são menos profundos. Isto pode indicar que não somente o $\mathrm{pH}$ pode contribuir para a contaminação bacteriana, mas também a profundidade, pois poços mais rasos teriam maiores chances de serem contaminados pela percolação de excretas fecais dispostas irregularmente no solo causando sua contaminação e consequentemente a lixiviação para dentro dos corpos hídricos. Uma limitação deste estudo foi a falta de informação sobre a profundidade dos poços, que não permitiu verificar uma possível associação.

\section{CONCLUSÕES}

O monitoramento visa avaliar a qualidade da água consumida pela população ao longo do tempo, o que nesse caso demonstrou que $100 \%$ das amostras não atendiam as condições de potabilidade previstas na Portaria de Consolidação no 5 de 28/09/2017 do Ministério da Saúde e, portanto, não ofertavam uma água de qualidade para a população das localidades estudadas.

As variáveis que mais influenciaram negativamente nesta qualidade foram o $\mathrm{pH}$ e a presença de bactérias do grupo coliformes fecais, como a presença de $E$. coli que torna a água imprópria para consumo humano, uma vez que está decorre da presença de fezes dos intestinos de animais e/ou humanos. Além disso, os parâmetros que estão diretamente relacionados à emissão de efluentes domésticos não tratados e 
resíduos resultantes de atividades industriais, principalmente pela construção de poços sem critérios técnicos adequados e vulnerabilidade do aquífero subterrâneo da região, apontam para fragilidade do recurso hídrico.

Estes fatores comprometem a qualidade da água e podem estar estreitamente associadas à profundidade do poço para captação da água, vulnerabilidade ambiental local, infiltração e lixiviação, portanto, tornando-se imprescindível a manutenção deste tipo de monitoramento para subsidiar estudos envolvendo diversas áreas multidisciplinares para que a população seja atendida com água potável de qualidade.

\section{REFERÊNCIAS}

ALVES, R. J.; ROCHA, L. C.; PONTES, A. N.; COSTA, M. S.; CAMPOS, P. S.. Estudo socioeconômico de comunidades da área do polo industrial de Barcarena, Pará, Brasil. Revista Enciclopédia Biosfera, Goiânia, v.11, n.21, p.3125-3136, 2015.

APHA. Standard Methods for Examination of Water and Wastwater. 23 ed. APHA, 2017.

AYRES, M.; AYRES-JR, M.; AYRES, D. L.; SANTOS, A. A. S.. Bioestat 5.0 aplicações estatísticas nas áreas das ciências biológicas e médicas. Belém: IDSM, 2007.

BAIRD, C.; CANN, M.. Química Ambiental. 4 ed. Porto Alegre: Bookman, 2011.

BRASIL. Portaria de Consolidação n. 5, de 28 de setembro de 2017, anexo XX. Consolidação das normas sobre as ações e os serviços de saúde do Sistema único de Saúde. Brasília, 2017.

CABRAL, J. P.. Water Microbiology. Bacterial Pathogens and Water. International Journal of Environmental Research and Public Health, v.7, n.10, p.3657-3703, 2010. DOI: https://doi.org/10.3390/ijerph7103657

CETESB. Guia Nacional de Coleta e Preservação de Amostras: Água, Sedimento, Comunidades Aquáticas e Efluentes Líquidos. São Paulo: CETESB; Brasília: ANA, 2011.

DACACH, N. G.. Sistemas Urbanos de Água. Rio de Janeiro: Livros Técnicos e Científicos, 1975.

FERREIRA, D. L. M.. Conflito pelo uso da água na Amazônia Brasileira: uma análise envolvendo a atividade minerometalúrgica e as comunidades Ilha São João e Curuperé no município de Barcarena-PA. Dissertação (Mestrado em Geografia) - Universidade Federal do Pará, Belém, 2015.

HAQUE, S. J.; ONODERA, S.; SHIMIZU, Y.. An overview of the effects of urbanization on the quantity and quality of groundwater in South Asian megacities. Limnology, v.14, n.2, p.135-145, 2013. DOI: https://doi.org/10.1007/s10201$\underline{012-0392-6}$

KATZ, B. G.; EBERTS, S. M.; KAUFFMAN, L. J.. Using Cl/Br rations and others indicators to asses potential impacts on groundwater quality from septic systems: a review and examples from principal aquifers in the United States.
Journal of Hydrology, v.397, n.3-4, p.151-166, 2011. DOI: https://doi.org/10.1016/j.jhydrol.2010.11.017

LUCAS, P. J.; CABRAL, C.; COLFORD JUNIOR, J. M.. Dissemination of Drinking Water Contamination Data to Consumers: A Systematic Review of Impact on Consumer Behaviors. PLOS ONE, v.6, n.6, p.e21098, 2011. DOI: https://doi.org/10.1371/journal.pone.0021098

MAIA, I. L. B.. O acesso à água potável como direito humano fundamental no direito brasileiro. Revista do CEPEJ, v.20, p.301-338, 2017.

MEDEIROS, A. C.; LIMA, M. O.; GUIMARÃES, R. M.. Avaliação da qualidade da água de consumo por comunidades ribeirinhas em áreas de exposição a poluentes urbanos e industriais nos municípios de Abaetetuba e Barcarena no estado do Pará, Brasil. Ciência \& Saúde Coletiva, v.21, n.3, p.695-708, 2016. DOI: http://doi.org/10.1590/1413$\underline{81232015213.26572015}$

OHE, W. V. D.; ODDO, L. P.; PIANA, M. L.; MORLOT, M.; MARTIN, P.. Harmonized methods of melissopalynology. Apidologie v.35, p.S18-S25, 2004. DOI: http://doi.org/10.1051/apido:2004050

OLIVEIRA FILHO, O. B. Q.; TORO, M. A. G.; SILVA, W. C. M.. Caracterização Hidrogeoquímica dos Sistemas Aquíferos Barreiras e Pirabas da Região Metropolitana de Belém (RMB) e investigação de possíveis misturas entre as águas. Cadernos de Geociências, v.14, n.1-2, p.8-23, 2018.

OLIVERO-VERBEL, J.; CARRANZA-LOPEZ, L.; CABALLEROGALLARDO, K.; RIPOLL-ARBOLEDA, A.; MUÑOZ-SOSA, D. Human exposure and risk assessment associated with mercury pollution in the Caqueta River, Colombian Amazon. Environ Sci. Pollut. Res. Int., v.23, n.20, p.20761-20771, 2016. DOI: http://doi.org/10.1007/s11356-016-7255-3

OMS. Organização Mundial da Saúde. Diretrizes para qualidade da água potável. 4 ed. Genebra: Organização Mundial da Saúde, 2011.

OUFLINE, R.; HAKKOU, R.; HANICH, L.; BOULARBAH, A.. Impact of human activities on the physico-chemical quality of surface water and groundwater in the north of Marrakech (Morocco). Environ Technol, v.33, n.16-18, p.2077-2088, 2012. DOI: http://doi.org/10.1080/09593330.2012.660644 
SALIH, A.. Qanats a Unique Groundwater Management Tool

in Arid Regions: The Case of Bam Region in Iran. Madrid: International Symposium on Groundwater Sustainability (ISGWAS), 2006.

SATTERTHWAITE, D.; MCGRANAHAN, G.; TACOLI, C.. Urbanization and its implications for food and farming. Philosophical Transactions of the Royal Society B-Biological Sciences, v.365, n.1554, p.2809-2820, 2010. DOI: http://doi.org/10.1098/rstb.2010.0136

SCALIZE, P. S.; BARROS, E. F. S.; SOARES, L. A.; HORA, K. E. R.; FERREIRA, N. C.; BAUMANN, L. R. F.. Avaliação da qualidade da água para abastecimento no assentamento de reforma agrária Canudos, Estado de Goiás. Ambiente e Agua, v.9, n.4, p.696-707, 2014. DOI: http://dx.doi.org/10.4136/ambiagua.1386

SHAHID, S. U.; IQBAL, J.; HASNAIN, G.. Groundwater quality assessment and its correlation with gastroenteritis using GIS: a case study of Rawal Town, Rawalpindi, Pakistan. Environ Monit Assess, v.186, n.11, p.7525-7537, 2014. DOI: http://doi.org/10.1007/s10661-014-3945-9

SINGH, S. K.; SRIVASTAVA, P. K.; SINGH, D.; HAN, D.; GAUTMAN, S. K.; PANDEY, A. C.. Modeling groundwater quality over a humid subtropical region using numerical indices, earth observation datasets, and X-ray diffraction technique: a case study of Allahabad district, India. Environ Geochem Health, v.37, n.1, p.157-180, 2015. DOI: https://doi.org/10.1007/s10653-014-9638-z
SILVA, C. N.; PALHETA, J. M.; RODRIGUES, J. C.. Perspectivas e análises do espaço geográfico: dinâmicas urbano-regionais e ordenamento territorial. 2 ed. Belém: UFPA, 2018.

SILVA, S. F.; HAZEU, M. T.. O complexo industrial-portuário em Barcarena e a saúde de comunidades tradicionais na Amazônia brasileira. O Social em Questão, v.44, n.22, p.171194, 2019.

SILVA, R. C. A.; ARAÚJO, T. M.. Qualidade da água do manancial subterrâneo em áreas urbanas de Feira de Santana (BA). Ciência \& Saúde Coletiva, v.8, n.4, p.1019-1028, 2003. DOI: http://dx.doi.org/10.1590/S1413$\underline{81232003000400023}$

SMAKA-KINCL, V.; STEGNAR, P.; LOVKA, M.; TOMAN, M. J.. The evaluation of waste, surface and ground water quality using the Allium test procedure. Elsevier, v.368, n.3-4, p.171-179, 1996. DOI: https://doi.org/10.1016/S0165 1218(96)90059-2

SOARES, J. B.; MAIA, A. C. F.. Água: microbiologia e tratamento. Fortaleza: UFC, 1999.

VASANTHAVIGAR, M.; SRINIVASAMOORTHY, K.; PRASANNA M. V.. Evaluation of groundwater suitability for domestic, irrigational, and industrial purposes: a case study from Thirumanimuttar river basin, Tamilnadu, India. Environ Monit Assess, v.184, n.1, p.405-420, 2012. DOI: http://doi.org/10.1007/s10661-011-1977-y

A CBPC - Companhia Brasileira de Produção Científica (CNPJ: 11.221.422/0001-03) detém os direitos materiais desta publicação. Os direitos referem-se à publicação do trabalho em qualquer parte do mundo, incluindo os direitos às renovações, expansões e disseminações da contribuição, bem como outros direitos subsidiários. Todos os trabalhos publicados eletronicamente poderão posteriormente ser publicados em coletâneas impressas sob coordenação da Sustenere Publishing, da Companhia Brasileira de Produção Científica e seus parceiros autorizados. Os (as) autores (as) preservam os direitos autorais, mas não têm permissão para a publicação da contribuição em outro meio, impresso ou digital, em português ou em tradução. 